\title{
Reação hansênica reversa associada à síndrome de reconstituição imune
}

\section{Leprosy reversal reaction in association with immune reconstitution inflammatory syndrome}

Karla Linhares Pinto ${ }^{1}$. José Wilson Accioly Filho². Márcia Gonçalves Brasil ${ }^{3}$. Thatiana Catunda Torres Mota ${ }^{1}$. Amanda Maria Menezes Dantas ${ }^{1}$. Alinne Mota Cavalcante ${ }^{1}$. Orisa Santos de Brito ${ }^{1}$.

1 Médica residente de Dermatologia, Hospital Universitário Walter Cantídio (HUWC), Universidade Federal do Ceará (UFC), Fortaleza, Ceará, Brasil. 2 Doutor em Dermatologia, Universidade Federal do Rio de Janeiro (UFRJ), Rio de Janeiro, Rio de Janeiro, Brasil. 3 Médica Dermatologista, Hospital Universitário Walter Cantídio (HUWC), Universidade Federal do Ceará (UFC), Fortaleza, Ceará, Brasil.

\section{RESUMO}

Hanseníase é uma doença causada pelo Mycobacterium leprae que afeta principalmente pele e nervos. Em muitos países subdesenvolvidos, a prevalência de HIV e Hanseníase tem aumentado, consequentemente o número de pessoas coinfectadas também. Relata-se o caso de uma paciente coinfectada por essas duas doenças apresentando quadro de úlceras profundas e muito dolorosas em antebraço direito 3 meses após a introdução de terapia antirretroviral. Após investigação para descartar outras causas de lesões cutâneas ulcerativas, a paciente obteve diagnóstico de reação reversa atípica fazendo parte de um quadro de síndrome de reconstituição imune. A paciente recebeu tratamento com prednisona e obteve resolução do quadro. Apesar da infecção pelo vírus HIV ter baixo impacto no desenvolvimento e evolução da Hanseníase, essa micobacteriose, bem como os quadros reacionais associados a ela, podem se apresentar como manifestação de síndrome de reconstituição imune.

Palavras-chave: Síndrome da reconstituição inflamatória imune. Hanseníase. Fármacos Anti-HIV.

\section{ABSTRACT}

Leprosy is a disease caused by Mycobacterium leprae that affects mainly skin and nerves. In many developing countries, the prevalence of HIV and Leprosy has increased and consequently the number of people with coinfection as well. Here we report the case of a patient coinfected by these two infectious diseases who presented deep painful ulcers in the right forearm three months after the start of antiretroviral therapy. After assessment to rule out other causes for the cutaneous ulcerative lesions, it was diagnosed an atypical paradoxical reaction of an immune reconstitution inflammatory syndrome. The patient was treated with prednisone and achieved remission of the symptoms. However infection with HIV is reported to have low impact on the development and evolution of Leprosy, this mycobacteriosis, as well as the reactions patterns associated with it, can be presented as a manifestation of immune reconstitution inflammatory syndrome.

Keywords: Immune reconstitution inflammatory syndrome. Leprosy. Anti-HIV agents.

Autor correspondente: Karla Linhares Pinto, Rua Almirante Rufino, 1450, Bloco Jatobá, apartamento 501, Montese, Fortaleza, Ceará. CEP: 60420-312. Telefone: +55 98 98174-0318/85 997277151. E-mail: karla.linhares@yahoo.com.br

Conflito de interesses: Não há qualquer conflito de interesses por parte de qualquer um dos autores.

Recebido em: 14 Nov 2016; Revisado em: 29 Dez 2016; Aceito em: 31 Mar 2017. 


\section{INTRODUÇÃO}

A Hanseníase é uma doença causada pelo Mycobacterium leprae, acomete principalmente pele e nervos e ainda é considerada um problema de saúde pública em muitos países subdesenvolvidos. Em alguns desses países a prevalência do vírus da imunodeficiência humana (HIV) tem aumentado e embora o número de coinfectados por essas duas condições não esteja bem estabelecido, a sobreposição geográfica de ambas provavelmente resulta em um incremento de casos de pessoas com as duas doenças. ${ }^{1}$

Após surgimento do HIV houve profundas mudanças na incidência e nos aspectos clínicos de diversas doenças, como por exemplo a Tuberculose, portanto, surgiu a preocupação em como a infecção por esse vírus poderia interferir na evolução da Hanseníase. Após vários estudos observou-se que em pacientes coinfectados uma condição parece não predispor ou piorar a outra. ${ }^{2}$

Alguns dos pacientes coinfectados tratados com terapia antirretroviral (TARV) apresentam quadro de reação hansênica tipo 1, também chamada de reação reversa, logo após melhora da imunidade, portanto, sugere-se que esse quadro reacional faça parte, nesses casos, da síndrome de reconstituição imune (SRI), ${ }^{3,4}$ fenômeno no qual o sistema imunológico começa a se recuperar, mas responde a uma infecção oportunista adquirida anteriormente com uma resposta inflamatória exacerbada. ${ }^{5,6}$ Nesses casos os pacientes devem manter o tratamento padrão para ambas as patologias.

O quadro de reação tipo 1 geralmente é autolimitado, mas em casos mais graves pode ser associado corticoterapia oral. ${ }^{6}$ No presente relato, descrevemos um caso de reação reversa atípica relacionada ao início da TARV, fazendo parte do quadro de SRI.

\section{RELATO DO CASO}

Relata-se o caso de uma paciente do sexo feminino de 28 anos de idade, que compareceu à primeira consulta com queixa de aparecimento de lesões cutâneas em região flexora de antebraço direito. As lesões correspondiam a uma placa eritematosa infiltrada apresentando centro tendendo à cura, de mais ou menos 15 x $7 \mathrm{~cm}$ com borda interna da lesão melhor delimitada que a borda externa, e outra placa menor, arredondada, de mais ou menos $3 \mathrm{~cm}$ de diâmetro, eritematosa e infiltrada, próxima à lesão descrita anteriormente (Figura 1). As lesões eram assintomáticas, mas ao exame apresentavam nítido comprometimento de sensibilidade térmica, sugerindo diagnóstico de Hanseníase. No restante do exame físico não havia outras lesões pelo corpo, nem espessamento de tronco nervosos.

A paciente referia ainda ter recebido diagnóstico de Síndrome da Imunodeficiência Adquirida (SIDA) pelo vírus HIV dois meses antes, confirmado através de teste de imunoensaio (ELISA) positivo e carga viral de 147578 cópias $/ \mathrm{ml}$. Apresentava, no momento do diagnóstico, contagem de linfócitos TCD4 de 31 células $/ \mu \mathrm{L}$, quando foi iniciado tratamento com Tenofovir, Lamivudina e Efavirenz, o qual realizava de forma regular.
Figura 1. Placa eritematosa e infiltrada em antebraço direito.

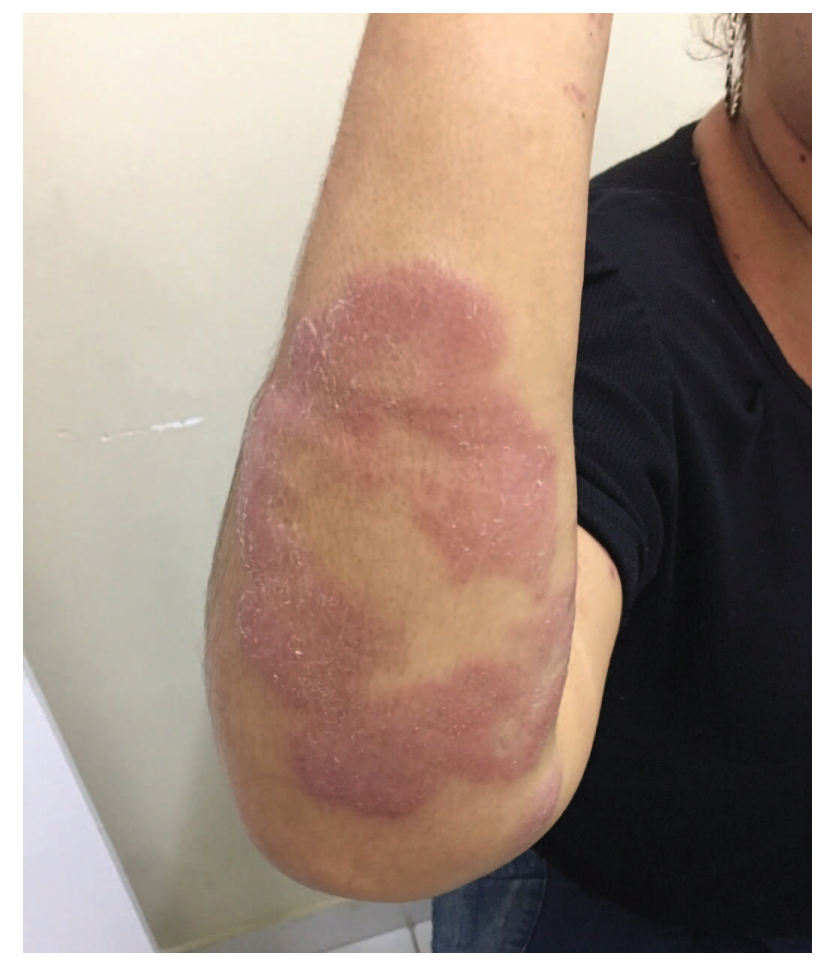

Para confirmar o diagnóstico das lesões de pele, foram realizadas pesquisa de bacilos álcool-ácido resistentes (BAAR) na linfa de lobos de orelhas, cotovelo esquerdo e lesão cutânea, a qual foi negativa, e biópsia de pele, que demonstrou presença de granulomas tuberculóide perianexiais e perineurais, sendo compatível com o diagnóstico de Hanseníase. Apesar de apresentar apenas duas lesões de pele, a paciente foi classificada como borderline tuberculóide pela classificação de Ridley e Jopplin, ${ }^{7}$ pois uma das lesões apresentava diâmetro maior que $10 \mathrm{~cm}$ e bordas mal definidas. Foi optado por iniciar tratamento com o esquema de Poliquimioterapia Multibacilar (PQT-MB), com Rifampicina, Dapsona e Clofazimina, por um ano.

Após um mês do início da PQT-MB, a paciente evoluiu com úlceras profundas, bem recortadas e muito dolorosas na área onde anteriormente se encontravam as placas eritematosas (Figura 2). Nesse momento a contagem de linfócitos TCD4 era de 135 células $/ \mu \mathrm{L}$ e carga viral de 66 cópias $/ \mathrm{ml}$. Foi realizada biópsia da lesão ulcerada que evidenciou infiltrado inflamatório linfohistioplasmocitário com área de necrose, arranjo granulomatoso e fibrose (Figuras 3 e 4), com coloração de Wade negativa para bacilos.

A história clínica e os achados histopatológicos fizeram com que fosse estabelecido o diagnóstico de reação hansênica tipo 1 como manifestação de síndrome de reconstituição imune. Iniciou-se prednisona $60 \mathrm{mg} / \mathrm{dia}$ e 45 dias após o início da corticoterapia, a paciente evoluiu com melhora importante do quadro, sendo iniciado redução gradual da medicação. Após a retirada da prednisona a lesão já estava em processo de reeptelização e após 3 meses do início do quadro a lesão já se encontrava completamente cicatrizada (Figura 5). 
Figura 2. Úlcera em antebraço direito.

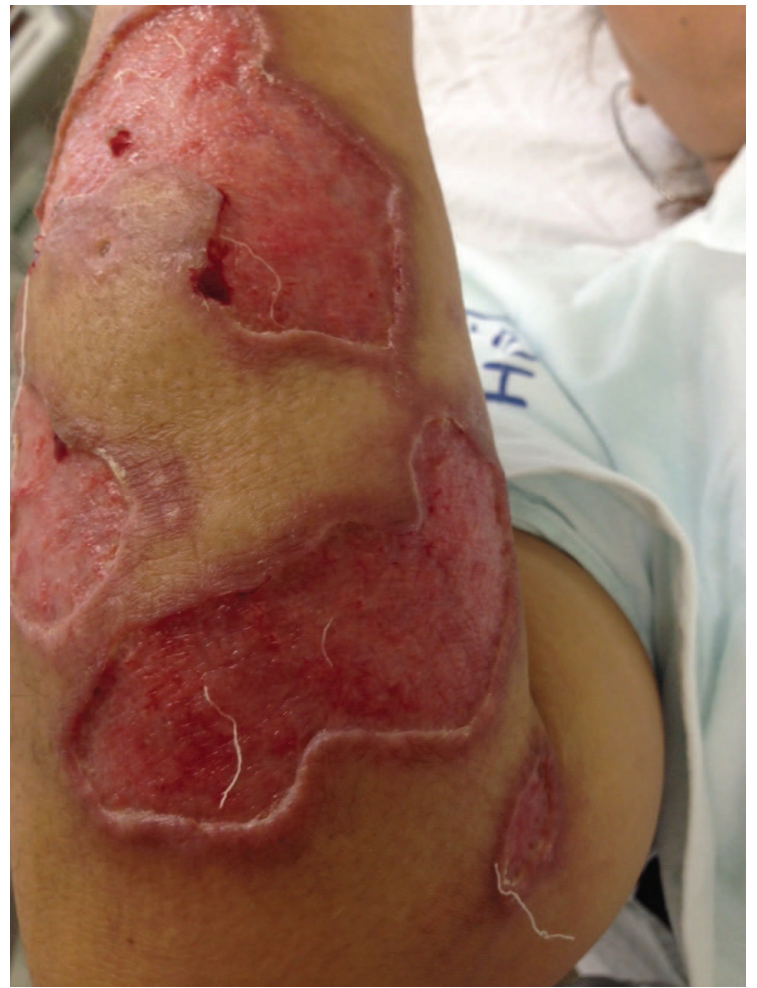

Figura 3. Exame Histopatológico evidenciando infiltrado inflamatório linfohistioplasmocitário em arranjo granulomatoso.

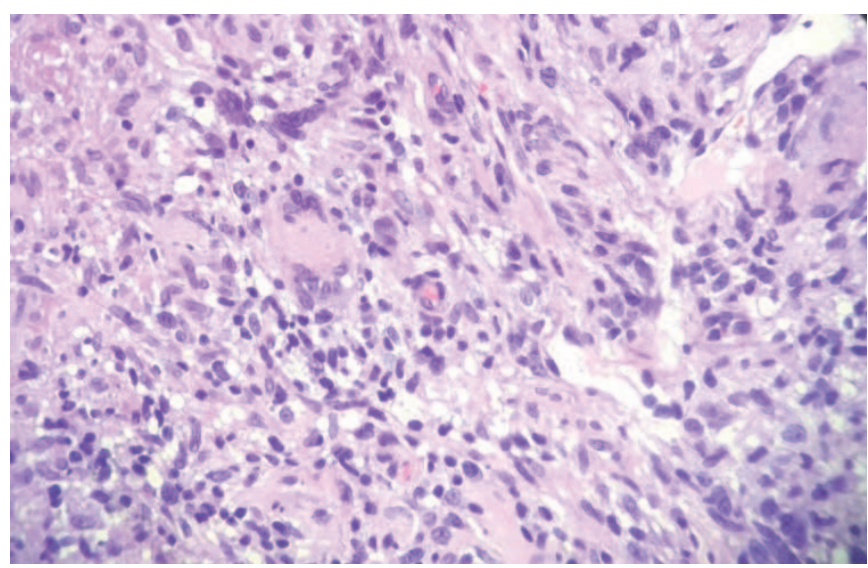

Figura 4. Histopatológico evidenciando infiltrado inflamatório linfohistioplasmocitário com área de necrose.

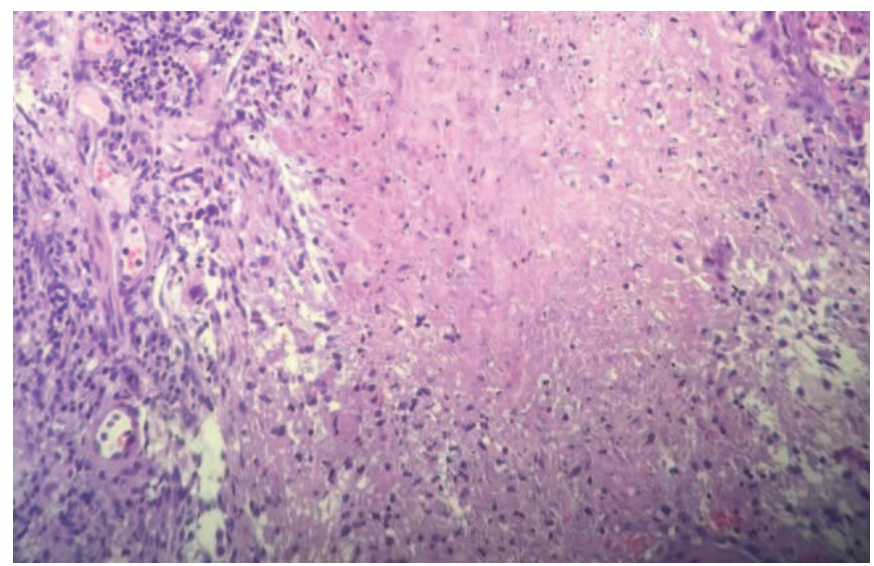

Figura 5. Cicatriz em áreas de úlceras prévias.

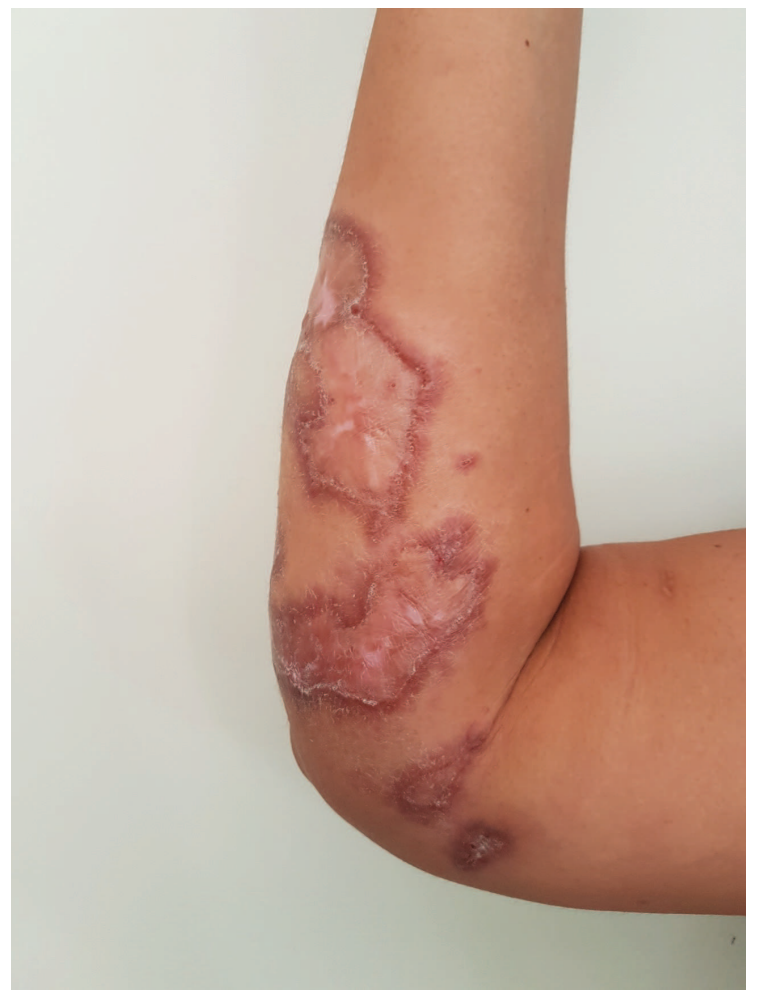

\section{DISCUSSÃO}

A síndrome da reconstituição Imune (SRI) é mais comumente encontrada em pacientes que iniciam terapia antirretroviral quando a contagem de linfócitos TCD4 está muito baixa, geralmente abaixo de 100 células $/ \mu \mathrm{L}$ e geralmente surge 1 a 6 meses após o início da TARV, principalmente durante um período de transição no qual há a redução da carga viral e aumento dos linfócitos TCD4, e consequente melhora da imunidade. ${ }^{5,8,9}$

Apesar da infecção pelo vírus HIV ter baixo impacto no desenvolvimento e evolução da Hanseníase, essa micobacteriose, bem como os quadros reacionais associados a ela, podem se apresentar, como manifestação de síndrome de reconstituição imune., ${ }^{2,3}$ Não existem critérios bem estabelecidos para o diagnóstico de reação hansênica, entretanto um estudo realizado em Recife, no estado de Pernambuco, avaliando 201 pacientes com história de quadro reacional, considerou para o diagnóstico de reação reversa pelo menos uma das seguintes manifestações clínicas: infiltração em lesões antigas de hanseníase acompanhadas de edema e dor, surgimento de novas lesões em forma de placas eritemato-infiltradas, tricofitóides com distúrbios de sensibilidade, ou espessamento em um ou mais nervos periféricos associado a quadro doloroso, podendo essas características estar associadas a outros achados, como febre, mal estar, hipersensibilidade palmar e plantar, lesões vésicobolhosas, ulceração e edema em mãos e pés. ${ }^{10}$

No exame histopatológico de lesões ulceradas associadas aos quadros reacionais pode haver além dos granulomas já existentes, edema na derme e aumento do infiltrado linfocitário 
e algumas vezes aumento do número de células de Langhans, áreas de necrose e erosão da epiderme. ${ }^{1}$ No caso apresentado, após aumento importante de linfócitos TCD4 e redução drástica da carga viral, a paciente evoluiu com um quadro de reação reversa agressivo com úlcera profunda e dolorosa. O exame histopatológico foi compatível com a hipótese de reação reversa.

\section{REFERÊNCIAS}

1 Pereira GA, Stefani MM, Araújo JA Filho, Souza LC, Stefani GP, Martelli CM. Human immunodeficiency virus type 1 (HIV-1) and mycobacterium leprae co-infection: HIV-1 subtypes and clinical, immunologic, and histopathologic profiles in a brazilian cohort. Am J Trop Med Hyg. 2004;71(5):679-84.

2 Pires CA, Jucá FO Neto, Albuquerque NC, Macedo GM, Batista $\mathrm{KN}$, Xavier MB. Leprosy reactions in patients coinfected with HIV: clinical aspects and outcomes in two comparative cohorts in the Amazon Region, Brazil. PLoS Negl Trop Dis. 2015;9(6): 1-14.

3 George A, Vidyadharan S. Hansen's disease in association with immune reconstitution inflammatory syndrome. Indian Dermatol Online J. 2016;7(1):29-31.

4 Arakkal GK, Damarla SV, Chanda GM. Immune reconstitution inflammatory syndrome unmasking erythema nodosum leprosum: a rare case report. Indian J Dermatol. 2015;60(1):106.

5 Blum L, Flageul B, Sow S, Launois P, Coll A, Millan J, et al. Leprosy reversal reaction in HIV-positive patients. Int J Lepr Other Mycobact Dis. 1993;61(2):214-7.
O tratamento preconizado em casos mais graves deste tipo de reação é de prednisona $1 \mathrm{mg} / \mathrm{kg}$ até melhora importante do quadro seguida da redução gradual da droga, ${ }^{8}$ apesar de muitos pacientes ainda se encontrarem com imunossupressão grave. O tratamento recomendado foi realizado na paciente do presente relato havendo resolução completa das lesões.

6 Ustianowski AP, Lawn SD, Lockwood DN. Interactions between HIV infection and Leprosy: a paradox. Lancet Infect Dis. 2006;6(6):350-60.

7 Ridley DS, Jopling WH. Classification of leprosy according to immunity. A five-group system. Int J Lepr Other Mycobact Dis. 1966;34(3):255-73.

8 Trindade MA, Manini MI, Masetti JH, Leite MA, Takahashi MD, Naafs B. Leprosy and HIV co-infection in five patients. Lepr Rev. 2005;76(2):162-6.

9 Couppié P, Abel S, Voinchet H, Roussel M, Hélénon R, Huerre M, et al. Immune reconstitution inflammatory syndrome associated with HIV and leprosy. Arch Dermatol. 2004;140(8):997-1000.

10 Teixeira MA, Silveira VM, França ER. Características epidemiológicas e clínicas das reações hansênicas em indivíduos paucibacilares e multibacilares, atendidos em dois centros de referência para hanseníase, na Cidade de Recife, Estado de Pernambuco. Rev Soc Bras Med Trop. 2010;43(3):287-92.

\section{Como citar:}

Pinto KL, Accioly JW Filho, Brasil MG, Mota TC, Dantas AM, Cavalcante AM, et al. Reação hansênica reversa associada à síndrome de reconstituição imune. Rev Med UFC. 2017 mai-ago;57(2):61-64. 